\title{
MARGIN DAN TINGKAT EFISIENSI PEMASARAN IKAN TENGGIRI (Scomberomorus commerson) DI PPI TANJUNGSARI KABUPATEN PEMALANG
}

\section{MARGIN AND EFFICIENCY LEVEL OF MARKETING OF MACKEREL (Scomberomorus commerson) IN PPI TANJUNGSARI PEMALANG}

\author{
Hendrik Anggi Setyawan, Bambang Argo Wibowo, Abdul Kohar Mudzakir \\ Departemen Perikanan Tangkap, \\ Fakultas Perikanan dan Ilmu Kelautan, Universitas Diponegoro \\ Korespondensi: hendrikanggisetyawan@live.undip.ac.id
}

\begin{abstract}
Mackerel is one of the main catch targets for gill net multifilament fishermen in PPI Tanjungsari due to its high price and also the demand of the market from inside and outside the Pemalang Regency. Mackerel's marketing business is carried out and developed by various parties, including fishermen, large traders, retailers, and out-of-town merchants. The purposes of this research were to find out the form of marketing channels and analyze the value of marketing margins, and marketing efficiency of mackerel in PPI Tanjungsari. The method used in this research was descriptive. The sampling method used in this study was the purposive sampling method. Data analysis was marketing margin analysis and marketing efficiency analysis. The result is that there are two forms of marketing channels for mackerel. The first marketing channel is from fishermen-medium traders-retailer-end consumers, and the second marketing channel is from fishermen-large traders-traders outside the city-consumers. The total marketing margin on the second channel is greater than the first channel, which is $\mathrm{Rp} 33.243,-/ \mathrm{kg}$ due to greater marketing costs. The marketing efficiency analysis obtained on both channels falls into the inefficient category with values of $20 \%$ on the first channel and $33 \%$ on the second channel.
\end{abstract}

Keywords: efficiency, mackerel, marketing, Pemalang

\begin{abstract}
ABSTRAK
Ikan Tenggiri menjadi salah satu target tangkapan utama bagi nelayan gill net multifilament di PPI Tanjungsari dikarenakan harganya yang tinggi dan juga permintaan pasar dari dalam maupun luar Kabupaten Pemalang yang banyak. Usaha pemasaran ikan Tenggiri dilakukan dan dikembangkan oleh berbagai pihak, diantaranya adalah nelayan, pedagang besar, pedagang pengecer, dan pedagang luar kota. Tujuan dari penelitian ini adalah untuk mengetahui bentuk saluran pemasaran serta menganalisis nilai marjin pemasaran dan efisiensi pemasaran ikan Tenggiri di PPI Tanjungsari. Metode penelitian yang digunakan adalah metode deskriptif, dan metode pengambilan sampel adalah metode purposive sampling. Analisis data yang dilakukan berupa analisis marjin pemasaran, fisherman's share, dan analisis efisiensi pemasaran. Terdapat dua bentuk saluran pemasaran ikan tenggiri, yaitu dari nelayan-pedagang sedang-pedagang kecil-konsumen akhir dan dari nelayan-pedagang besar-pedagang luar kota-konsumen. Total marjin pemasaran pada saluran kedua lebih besar dibandingkan saluran pertama, yaitu sebesar $\mathrm{Rp} 33.243$,- / kg dikarenakan biaya pemasaran yang lebih besar. Analisis efisiensi pemasaran yang didapatkan pada kedua saluran termasuk dalam kategori tidak efisien dengan nilai $20 \%$ pada saluran 1 dan $33 \%$ pada saluran 2 .
\end{abstract}

Kata kunci: efisiensi, Pemalang, pemasaran, tenggiri 


\section{PENDAHULUAN}

Kabupaten Pemalang memiliki potensi perikanan laut yang melimpah. Berdasarkan data BPS Jawa Tengah (2017), Kabupaten Pemalang memiliki rata-rata produksi perikanan laut yang dijual di TPI tertinggi di Jawa Tengah setelah Kabupaten Rembang, Kota Tegal, Kabupaten Pati, dan Kabupaten Batang dengan rata-rata penjualan sebesar 6,17 juta ton ikan per triwulan per TPI. Hasil tangkapan yang mendominasi di Kabupaten Pemalang adalah ikan tembang, kembung, layur, selar, tongkol, dan tenggiri. Pada Kabupaten Pemalang terdapat 1 Pelabuhan Perikanan Pantai (PPP), yaitu PPP Asemdoyong, dan 4 Pangkalan Pendaratan Ikan (PPI), yaitu PPI Tanjungsari, PPI Mojo, PPI Ketapang, dan PPI Tasikrejo.

Dilihat dari data produksi dan nilai produksi tiap tahunnya, PPI Tanjungsari merupakan PPI dengan jumlah produksi terbesar di Kabupaten Pemalang dibandingkan PPI lainnya. Jumlah produksi ikan Tenggiri yang didaratkan di TPI Tanjungsari pada tahun 2018 sebesar $478.201 \mathrm{~kg}$ dan nilai produksi sebesar Rp 12.738.656.000,- yang didominasi dari hasil tangkapan nelayan gill net multifilament (DKP Kabupaten Pemalang 2019). Hasil tangkapan ikan yang didapatkan oleh nelayan langsung masuk di Tempat Pelelangan Ikan (TPI) Tanjungsari yang kemudian didistribusikan baik untuk kebutuhan lokal maupun luar daerah.

Ikan Tenggiri (Scomberomorus commersoni) menjadi salah satu target tangkapan utama bagi nelayan gill net multifilament di PPI Tanjungsari dikarenakan harganya yang tinggi dan juga permintaan pasar dari dalam maupun luar Kabupaten Pemalang yang banyak. Hal ini sesuai dengan pernyataan Yusrin et al. (2017), ikan tenggiri (Scomberomorus commersoni) banyak tertangkap di Perairan Indonesia, seperti pantai utara Jawa. Harga ikan Tenggiri di Kabupaten Pemalang berkisar antara Rp 45.000 - Rp 50.000,-/kg. Hasil analisis LQ (Location Quotient) didapatkan bahwa ikan Tenggiri adalah komoditas basis di Kabupaten Pemalang dan dapat menyuplai kebutuhan ikan Tenggiri ke luar daerah.

Kegiatan yang penting dalam usaha perikanan adalah pemasaran karena dapat mempengaruhi naik turunnya pendapatan nelayan. Pemasaran harus baik dan efisien agar harga yang didapatkan tinggi (Ismail et al. 2008). Menurut Mubyarto (2002) dalam Sudana (2019), pemasaran bisa dikatakan efisien apabila barang yang dijual dari produsen dapat tersampaikan ke konsumen dengan harga yang serendah-rendahnya, dan semua pihak yang terlibat pada proses produksi serta tata niaga barang tersebut mendapatkan bagian yang adil dari harga keseluruhan yang dibayarkan oleh konsumen akhir.

Usaha pemasaran ikan Tenggiri dilakukan dan dikembangkan oleh berbagai pihak, diantaranyaadalah nelayan, pedagang besar, dan pedagang pengecer. Tingginya produksi dapat mengakibatkan terjadinya kegiatan pemasaran yang melibatkan beberapa lembaga pemasaran. Hal tersebut mengakibatkan saluran pemasaran menjadi kurang efisien, dikarenakan setiap lembaga pemasaran akan mengambil keuntungan untuk menutup biaya pemasaran yang harus dikeluarkan dan marjin pemasarannya pun semakin besar. Akibatnya harga di tingkat konsumen akhir akan semakin tinggi, dan harga jual ikan di tingkat nelayan akan semakin ditekan karena daya beli konsumen yang terbatas. Dari permasalahan tersebut, perlu dilakukan suatu penelitian mengenai kegiatan pemasaran ikan Tenggiri yang ada di PPI Tanjungsari Kabupaten Pemalang. Tujuan dari penelitian ini adalah untuk mengetahui bentuk saluran pemasaran serta menganalisis nilai marjin pemasaran dan efisiensi pemasaran ikan Tenggiri di PPI Tanjungsari.

\section{METODE PENELITIAN}

\section{Waktu dan tempat penelitian}

Penelitian ini dilaksanakan pada bulan Januari 2019 sampai dengan Februari 2019, bertempat di PPI Tanjungsari, Kabupaten Pemalang, Jawa Tengah. Peta lokasi penelitian dapat dilihat pada Gambar 1.

\section{Metode pengumpulan data dan penentuan sampel}

Metode yang digunakan dalam penelitian ini adalah metode deskriptif yang bersifat studi kasus. Pengamatan yang dilakukan meliputi alur pemasaran ikan Tenggiri, marjin pemasaran, serta aspekaspek pendukung lainnya seperti jumlah dan nilai produksi ikan Tenggiri dan harga ikan Tenggiri. 


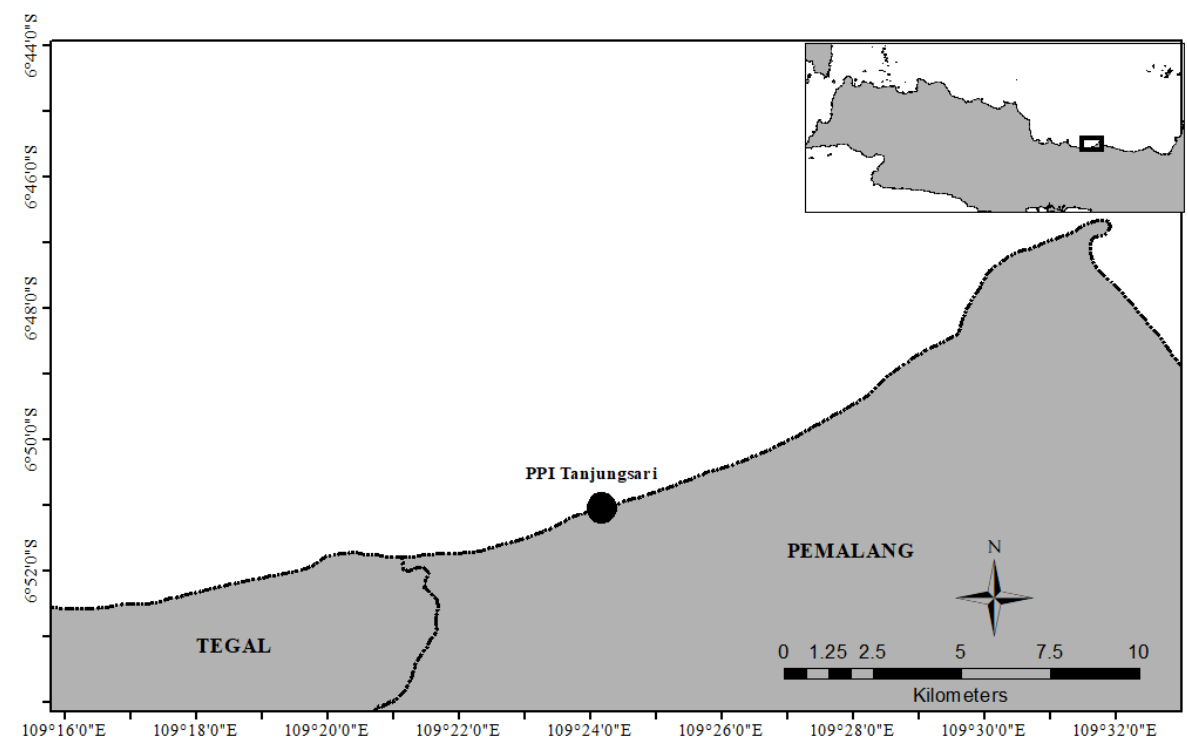

Gambar 1. Peta Lokasi Penelitian

Metode pengambilan sampel yang digunakan pada penelitian ini adalah metode purposive sampling. Purposive sampling adalah metode pemilihan sampel tidak acak dengan pertimbangan-pertimbangan tertentu dan menyesuaikan dengan tujuan atau permasalahan penelitian (Sugiyono 2012). Populasi dalam penelitian ini adalah semua pelaku usaha yang terlibat dalam pemasaran hasil tangkapan ikan Tenggiri (Scomberomorus commersoni) di PPI Tanjungsari yaitu nelayan gill net multifilament, pedagang skala besar, pedagang skala sedang, pedagang skala kecil, dan pedagang luar kota. Berdasarkan data jumlah nelayan yang ada di DKP Kabupaten Pemalang (2019), pedagang diklasifikasikan berdasarkan jumlah modal beli ikan. Pedagang skala besar adalah pedagang yang memiliki modal usaha per hari > Rp 15.000.000,00 sedangkan untuk pedagang skala sedang memiliki modal usaha per hari antara Rp 2.000.000,00 hingga Rp 15.000.000,00 dan untuk pedagang skala kecil memiliki modal usaha per hari < Rp 2.000.000,00. Berdasarkan kriteria-kriteria tersebut, jumlah sampel yang diambil yaitu 34 nelayan, 2 pedagang skala besar, 10 pedagang skala sedang, 20 pedagang skala kecil, dan 3 pedagang luar kota.

\section{Metode analisis data}

Analisis data yang dilakukan dalam penelitian ini adalah sebagai berikut:

\section{Saluran Pemasaran}

Saluran pemasaran ikan Tenggiri di PPI Tanjungsari dianalisis secara deskriptif kualitatif untuk memperlihatkan saluran pemasaran ikan dari nelayan hingga tingkat konsumen akhir. Tujuan dari analisis ini adalah untuk mengetahui lembaga pemasaran yang terlibat dan pola saluran pemasaran yang terjadi pada proses tersebut.

2. Marjin Pemasaran

Marjin pemasaran merupakan selisih harga yang dibayar kepada produsen dan harga yang dibayar oleh konsumen (Hanafiah \& Saefudin 1986). Rumus yang digunakan adalah sebagai berikut:

$$
M_{i}=H K_{i}-H P_{i}
$$

Keterangan:

$M_{i} \quad=$ Marjin pemasaran tingkat ke- $i(\mathrm{Rp} /$ $\mathrm{kg})$

$H K_{i}=$ Harga beli konsumen tingkat ke- $i$ (Rp/kg)

$H P_{i}=$ Harga jual produsen tingkat ke- $i$ $(\mathrm{Rp} / \mathrm{kg})$

3. Efisiensi pemasaran

Analisis ini digunakan untuk mengetahui efisiensi pemasaran pada setiap lembaga yang terlibat. Menurut Soekartawi (2002) rumus efisiensi pemasaran adalah sebagai berikut:

$$
E P=\frac{B P}{H E} \times 100 \%
$$

Keterangan:

$\mathrm{EP}=$ Efisiensi pemasaran

$\mathrm{BP}=$ Biaya pemasaran

$\mathrm{HE}=$ Harga eceran (di tingkat konsumen akhir)

Pemasaran dapat dikatakan efisien apabila hasil perhitungan Efisiensi 
Pemasaran (EP) adalah $<5 \%$, sedangkan pemasaran tidak efisien apabila hasil perhitungan memiliki nilai $>5 \%$.

\section{HASIL DAN PEMBAHASAN}

\section{Armada penangkapan}

Armada penangkapan yang berpangkalan di PPI Tanjungsari Kabupaten Pemalang didominasi oleh kapal dengan alat tangkap trammel net dan gill net dengan ukuran kapal $\leq 6$ GT dan juga kapal purse seine dengan ukuran kapal $\leq 15$ GT. Jumlah armada penangkapan di PPI Tanjungsari dibedakan menjadi 2, yaitu kapal motor dan perahu motor tempel. Grafik jumlah armada penangkapan dapat dilihat pada Gambar 2.

Berdasarkan data DKP Kabupaten Pemalang (2019), jumlah armada penangkapan yang ada di PPI Tanjungsari mengalami peningkatan yang cukup besar, yang semula pada tahun 2017 berjumlah 475 unit menjadi 925 unit pada tahun 2018. Dari seluruh jumlah kapal aktif pada tahun 2018, terdapat 67,9\% kapal trammel net, 21,2\% kapal gill net, 3,3\% kapal purse seine, 1,6\% kapal pancing ulur, dan 6,0\% kapal alat tangkap lainnya.

\section{Nelayan}

Nelayan adalah suatu kelompok masyarakat yang kehidupannya bergantung langsung pada hasil laut, dengan cara melakukan penangkapan ikan sebagai mata pencaharian. Berdasarkan data dari DKP
Kabupaten Pemalang (2019), nelayan yang ada di PPI Tanjungsari terdiri dari nelayan juragan $(7,4 \%)$, pandega $(67,7 \%)$, sambilan $(20,1 \%)$, dan nelayan yang hanya melaut saat-saat tertentu saja $(4,8 \%)$. Nelayan juragan adalah nelayan yang memiliki kapal, mesin, dan alat tangkap sendiri (ada yang ikut melakukan penangkapan di laut dan ada pula yang hanya menyediakan armada penangkapannya). Nelayan pandega merupakan nelayan yang memiliki kemampuan menangkap ikan namun tidak memiliki alat produksi. Nelayan sambilan merupakan nelayan yang pekerjaannya sebagai nelayan, namun memiliki pekerjaan lain seperti buruh pabrik. Terdapat pula nelayan yang melakukan aktivitas penangkapan pada saat-saat tertentu ketika memang dibutuhkan. Jumlah nelayan di PPI Tanjungsari dari tahun 2014-2018 dapat dilihat pada Gambar 3.

Ikan Tenggiri yang dilelang di TPI Tanjungsari didominasi oleh hasil tangkapan nelayan yang menggunakan alat tangkap gill net multifilament. Menurut data Dinas Kelautan dan Perikanan Kabupaten Pemalang (2019), terdapat $438.172 \mathrm{~kg}$ ikan Tenggiri yang dilelang di PPI Tanjungsari dan 98,9\% diantaranya adalah hasil tangkapan nelayan gill net multifilament, sedangkan 1,1\% lainnya merupakan hasil tangkapan nelayan purse seine dan pancing ulur. Ikan Tenggiri merupakan target tangkapan utama dari nelayan gill net multifilament dan menjadi primadona dikarenakan harganya yang relatif tinggi, dan juga permintaan pasar yang banyak dari dalam maupun luar Kabupaten Pemalang.

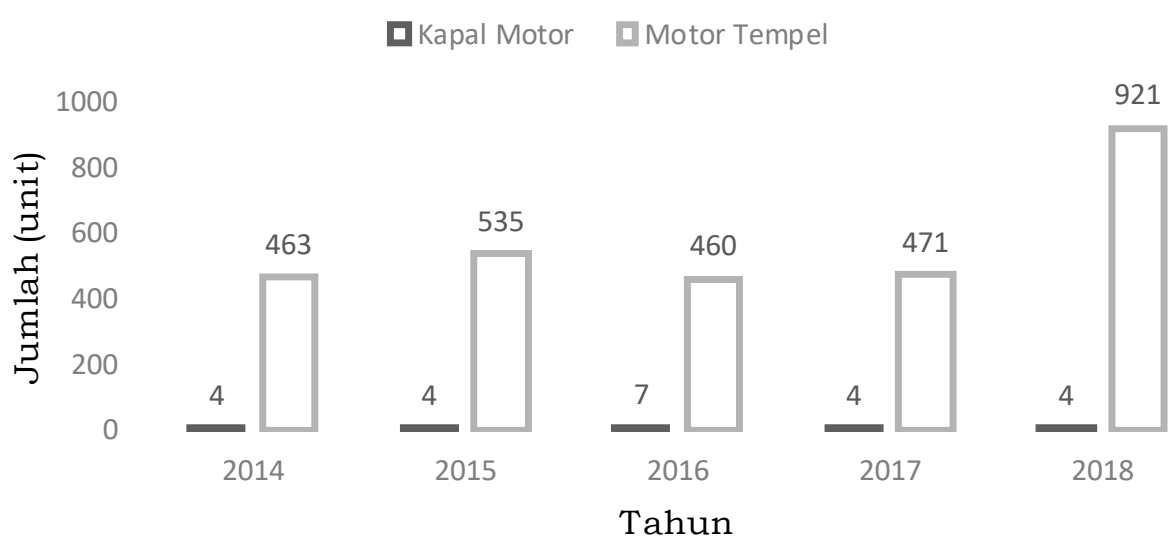

Gambar 2. Jumlah armada penangkapan di PPI Tanjungsari

(DKP Kabupaten Pemalang 2019) 


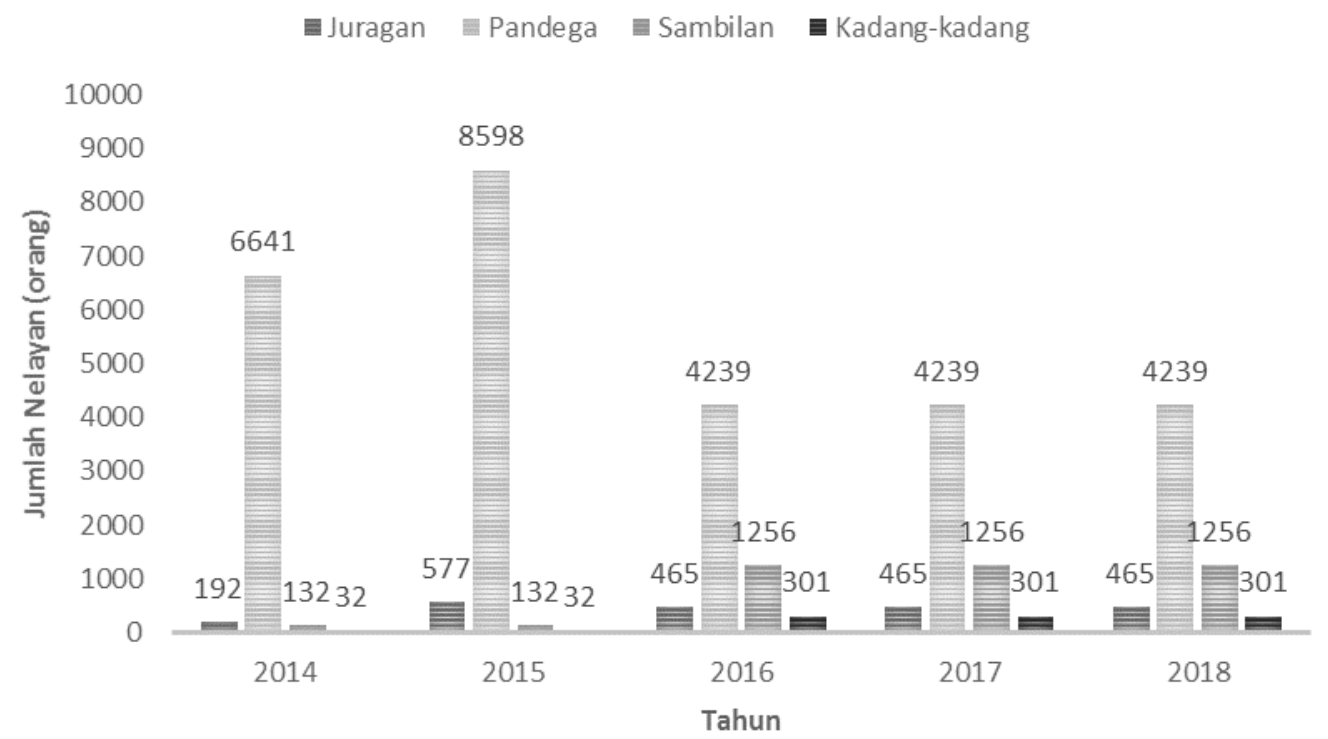

Gambar 3. Jumlah nelayan di PPI Tanjungsari (DKP Kabupaten Pemalang 2019)

\section{Pedagang}

Pedagang ikan di PPI Tanjungsari terbagi menjadi 3 macam berdasarkan modal usahanya, yaitu pedagang skala besar $(8,2 \%)$, pedagang skala sedang $(30,6 \%)$, dan pedagang skala kecil atau pengecer $(61,2 \%)$. Pedagang skala besar biasanya menjual ikan tenggiri ke luar kota seperti Jakarta. Pedagang skala sedang menjual ikan tenggiri ke pedagang skala kecil (pengecer). Adapun pedagang skala kecil (pengecer) biasanya menjual ikan tenggiri langsung ke konsumen. Jumlah pedagang ikan di PPI Tanjungsari tiap tahunnya mengalami perubahan yang dapat dilihat pada Gambar 4.

\section{Harga ikan tenggiri}

Harga ikan Tenggiri di PPITanjungsari ditentukan melalui proses pelelangan. Kegiatan lelang di TPI Tanjungsari dilakukan hanya sekali dalam sehari, dimulai dari pukul 07.00-selesai. Jika jumlah hasil tangkapan yang dilelang cukup banyak, maka proses lelang baru selesai hingga pukul 13.00 WIB. Namun, jika jumlah hasil tangkapan sedikit, proses lelang selesai pukul 10.00 WIB. Musim berpengaruh terhadap proses penjualan ikan Tenggiri di PPI Tanjungsari. Saat musim barat, banyak nelayan yang tidak melakukan aktivitas penangkapan. Hal ini mengakibatkan tidak adanya lelang di TPI Tanjungsari. Saat tidak ada lelang, beberapa pedagang hanya mengandalkan penjualan dari ikan tenggiri yang disimpan dalam bentuk beku.
Pendapatan nelayan sangat bergantung dari hasil lelang di TPI. Berdasarkan Gambar 5 harga ikan sangat dipengaruhi oleh jumlah produksi. Jumlah produksi yang tinggi mengakibatkan harga yang terbentuk menjadi rendah. Sebagai contoh pada Bulan Maret, jumlah produksi ikan tenggiri yang tinggi, maka harga yang dihasilkan hanya berkisar Rp 50.000,00, sedangkan pada Bulan Agustus dimana produksi ikan tenggiri rendah, didapatkan harga berkisar Rp 80.000,00.

Tingkat kenaikan harga pada ikan tenggiri di PPI Tanjungsari juga dipengaruhi oleh permintaan dan pangsa pasar yang berbeda. Hal ini sesuai dengan penelitian Huda et al. (2015) menyatakan bahwa ikan kakap merah memiliki harga yang lebih tinggi dibandingkan dengan tongkol dikarenakan pangsa pasar ikan tongkol hanya untuk pasar tradisional dan dipasarkan dalam bentuk segar utuh. Sedangkan ikan kakap merah memiliki pangsa pasar di restoran, pasar tradisional (dalam bentuk ikan segar utuh), maupun menjadi komoditas ekspor (dalam bentuk fillet).

Permasalahan yang muncul dalam penentuan harga ikan Tenggiri selanjutnya adalah posisi tawar nelayan yang rendah dibandingkan pedagang, sehingga keuntungan yang didapat oleh nelayan tidak optimal. Permasalahan yang hampir sama terdapat pada sistem pemasaran yang ada di Istanbul, Turki. Menurut Kaygisiz \& Eken (2018), salah satu permasalahan paling penting dari sistem pemasaran yang ada disana adalah kurangnya organisasi nelayan yang menyebabkan nilai tawar nelayan 
menjadi rendah dan memiliki kontribusi yang sedikit dalam penentuan harga. Nelayan menerima harga yang ditentukan oleh pedagang pengumpul. Kondisi ini menyebabkan pendapatan nelayan menjadi menurun. Penjualan secara langsung sebenarnya akan menjadi keuntungan bagi nelayan maupun konsumen. Tetapi faktanya pedagang menguasai sistem pemasaran dan adanya biaya tambahan pajak yang menyebabkan marjin pemasaran meningkat yang disebabkan karena harga ikan yang ikut naik.

Harga ikan bisa dikendalikan apabila informasi harga pasar dapat disediakan secara lengkap, baik melalui TPI maupun melalui kelompok nelayan agar bisa menjadi acuan dalam menentukan harga. Hal ini sesuai dengan pernyataan Sarwanto et al. (2014) yang menyebutkan bahwa penyediaan informasi harga tersebut diharapkan mampu berdampak pada peningkatan harga yang didapatkan oleh nelayan, sehingga terjadi peningkatan efisiensi pemasaran dan pendapatan nelayan.

\section{Saluran pemasaran}

Menurut Swastha (2002), saluran pemasaran adalah urutan lembaga pemasaran yang dilalui produk yang telah dihasilkan sampai ke konsumen akhir. Saluran pemasaran memiliki bentuk sederhana maupun rumit, dan biasanya memiliki lebih dari satu macam saluran pemasaran, tergantung dari produk yang dihasilkan. Kegiatan saluran pemasaran merupakan suatu tindakan ekonomi yang mendasarkan pada kemampuannya untuk membantu penciptaan nilai ekonomi, sedangkan nilai ekonomi itu sendiri berfungsi untuk menentukan harga barang dan jasa kepada individu-individu yang terlibat.

Berdasarkan Gambar 6 dapat terlihat bahwa saluran pemasaran ikan tenggiri di PPI Tanjungsari terdapat 2 saluran. Untuk saluran yang pertama ikan Tenggiri yang berasal dari nelayan dibeli oleh pedagang skala sedang melalui proses lelang di TPI yang kemudian dijual ke pedagang skala kecil dan nantinya akan dijual ke konsumen lokal di Kabupaten Pemalang. Saluran yang kedua ikan Tenggiri yang didapatkan oleh nelayan dilelang di TPI, yang selanjutnya dibeli oleh pedagang skala besar dan dijual ke pedagang yang berada di luar Kabupaten Pemalang yang nantinya akan dijual ke konsumen luar Kabupaten Pemalang, seperti Jakarta, Lampung, dan Palembang. Kedua saluran pemasaran ikan Tenggiri tersebut termasuk ke dalam saluran distribusi dua tingkat. Hal ini sesuai dengan pernyataan Kotler (2005) menyebutkan yang dimaksud dengan saluran distribusi dua tingkat adalah rantai pemasaran yang terdiri dari pedagang pengumpul dan pedagang pengecer.

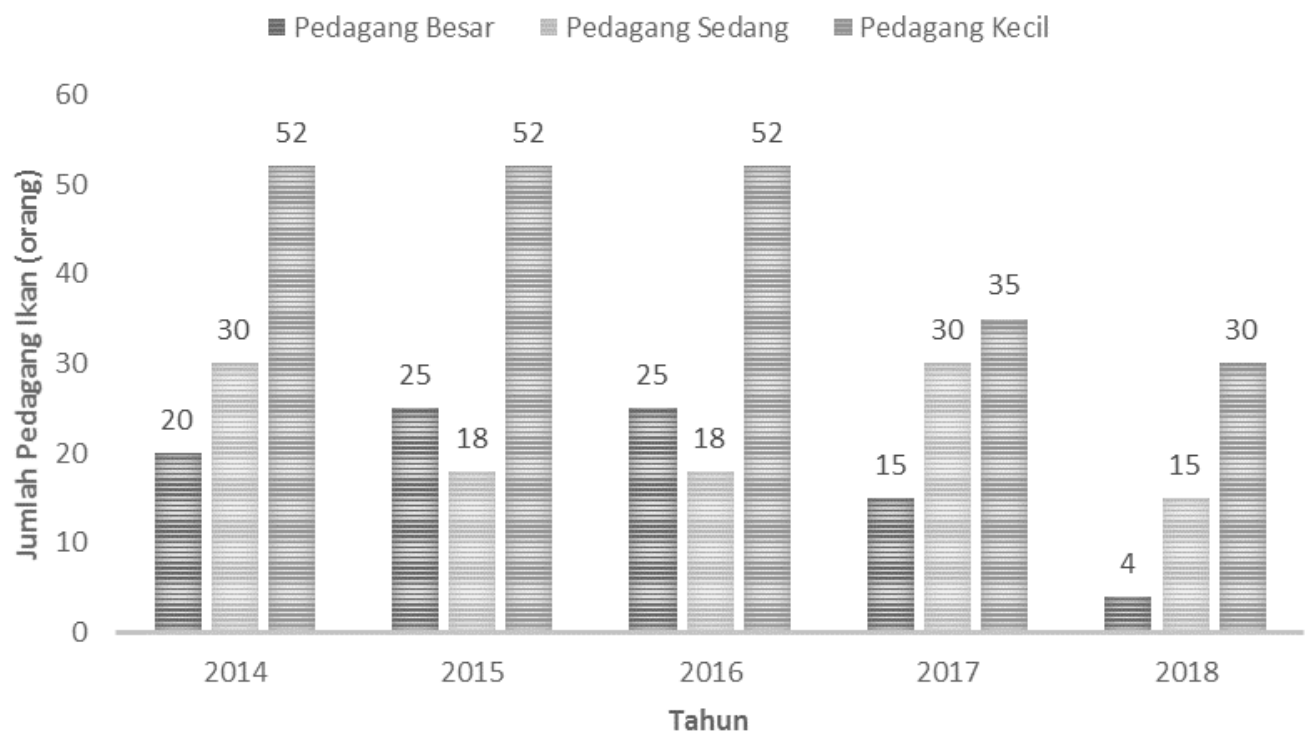

Gambar 4. Jumlah pedagang di PPI Tanjungsari (DKP Kabupaten Pemalang 2019) 


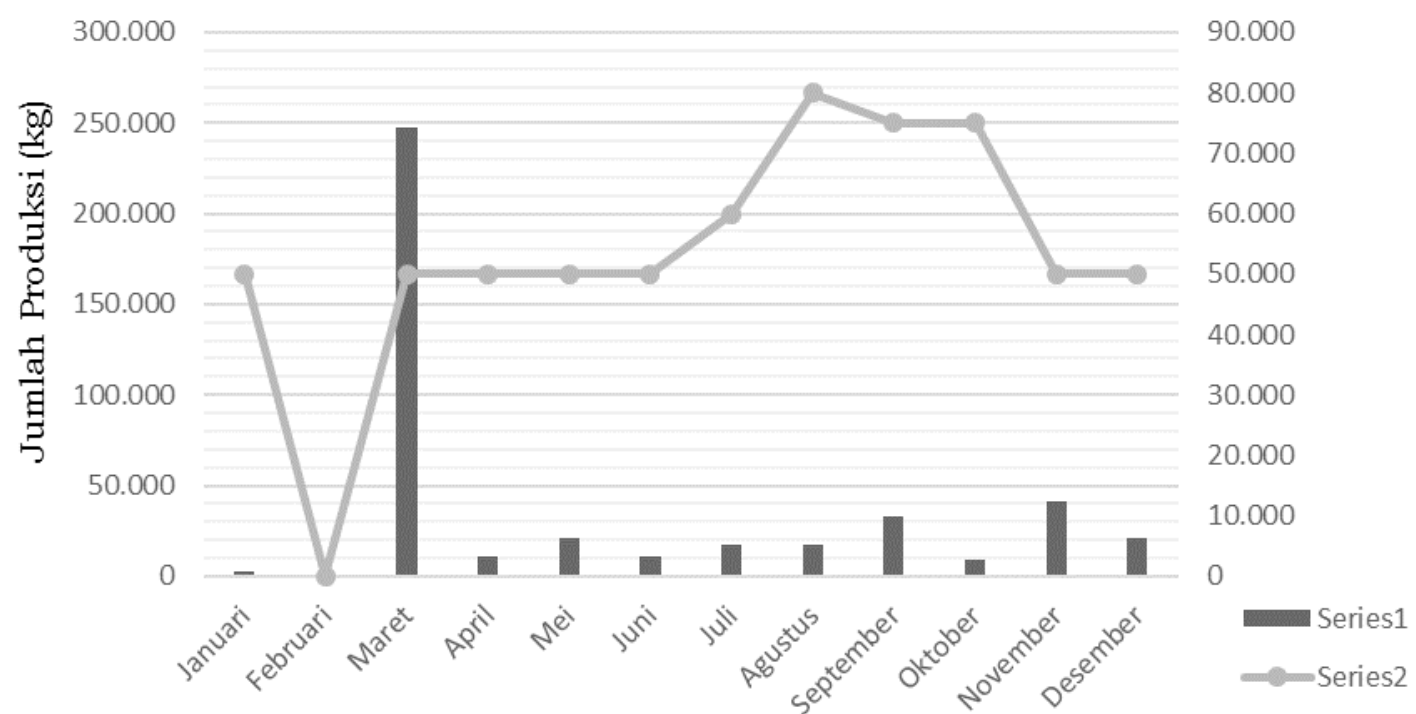

Gambar 5. Produksi dan harga ikan tenggiri tahun 2018 di PPI Tanjungsari (DKP Kabupaten Pemalang 2019)

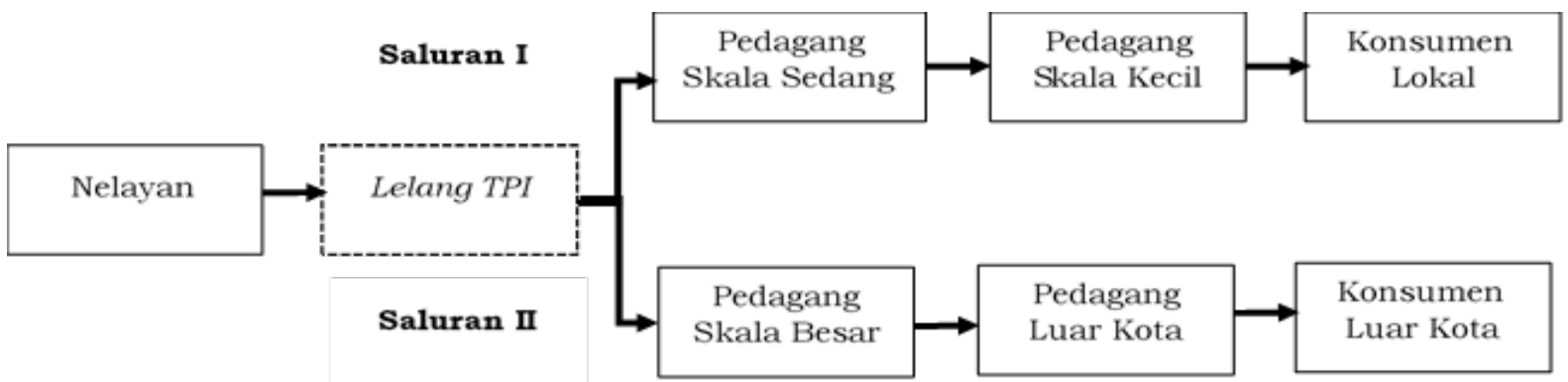

Gambar 6. Saluran pemasaran ikan tenggiri di PPI Tanjungsari

Semakin banyaknya pelaku pemasaran yang terlibat didalamnya biasanya akan membuat rantai pemasaran semakin panjang, sehingga dapat berakibat pada ketidakefisienan pada sistem pemasaran tersebut. Rantai pemasaran yang melibatkan banyak pelaku pemasaran dan tidak adanya batas harga yang diatur akan mengakibatkan harga ikan tenggiri cenderung tidak stabil. Hal ini sesuai dengan pernyataan Rasidin dan Rahman (2018) bahwa saluran pemasaran yang terjadi membuat harga yang berbedabeda pada tingkat konsumen akhir di tiap salurannya. Perbedaan tersebut ditentukan oleh perlakuan dan penanganan produk pada tiap saluran yang berakibat pada perbedaan marjin pemasaran dan marjin keuntungan yang diperoleh.

\section{Marjin pemasaran}

Kegiatan pemasaran ikan Tenggiri di PPI Tanjungsari melalui 2 saluran pemasaran dan melibatkan beberapa pelaku usaha baik dari dalam kabupaten Pemalang maupun luar kabupaten Pemalang, sehingga presentase marjin pada tiap saluran pemasaran berbeda. Hasil analisis marjin pemasaran pada sistem pemasaran hasil tangkapan ikan Tenggiri di PPI Tanjungsari, Pemalang dapat dilihat pada Tabel 1 .

Berdasarkan Tabel 1 tiap saluran pemasaran memiliki margin pemasaran yang berbeda sesuai kemampuan saluran pemasaran tersebut. Total marjin pemasaran pada saluran 1 sebesar Rp 22.626,-/ kg, yang terdiri atas pedagang sedang yang menjual ke pedagang kecil memiliki marjin pemasaran sebesar $\mathrm{Rp} 14.676,-/ \mathrm{kg}$, dan pedagang skala kecil yang menjual ke konsumen lokal di sekitar PPI Tanjungsari memiliki marjin pemasaran sebesar Rp 7.950,-/kg. Pada saluran 2, total marjin pemasaran sebesar Rp 33.243,-/ kg yang terdiri dari pedagang besar yang menjual ke pedagang luar kota memiliki marjin pemasaran sebesar Rp $21.576,-/ \mathrm{kg}$, dan pedagang luar kota yang menjual ke konsumen akhir memiliki marjin pemasaran sebesar Rp 11.667,-/ kg.

Marjin pemasaran terendah terdapat pada saluran pedagang skala 
kecil atau pengecer yang menjual ke konsumen akhir. Rendahnya marjin pemasaran yang didapatkan pedagang kecil dikarenakan volume produksi yang rendah, dan biaya pemasaran yang kecil. Hal ini sesuai dengan pernyataan Hapsari (2014) marjin pemasaran dipengaruhi oleh volume produksi, harga per kilogram, biaya pemasaran, serta musim. Margin yang semakin besar akan mengakibatkan semakin besar pula beban yang ditanggung oleh konsumen akhir. Harga yang harus dibayarkan oleh konsumen akhir pada saluran 1 maupun saluran 2 juga termasuk tinggi, sehingga pemasaran ikan Tenggiri pada PPI Tanjungsari bisa dikatakan tidak efisien. Menurut Mubyarto (2002) dalam Sudana (2019), pemasaran bisa dikatakan efisien apabila barang yang dijual dari produsen dapat tersampaikan ke konsumen dengan harga yang serendah-rendahnya.

Pedagang skala sedang pada saluran 1 biasanya akan memasukkan ikan Tenggiri ke dalam freezer, selain agar kualitas ikan Tenggiri masih tetap terjaga, tetapi juga menjaga ketersediaan ikan Tenggiri di pasar. Ketika musim paceklik dan tidak ada proses lelang, pedagang skala sedang masih tetap bisa menjual ikan Tenggiri yang telah dibekukan di dalam freezer sehingga proses perdagangan masih bisa berjalan. Perlakuan dalam menjaga kualitas ikan Tenggiri tersebut juga menyebabkan marjin pemasaran semakin besar. Menurut Huda et al. (2015) biaya resiko ikan tidak terjual dan biaya transportasi juga termasuk ke dalam faktor yang mempengaruhi marjin pemasaran ikan.

\section{Efisiensi pemasaran}

Efisiensi pemasaran adalah tujuan akhir yang akan dicapai dalam sistem pemasaran, dimana sistem pemasaran memberikan keuntungan kepada tiap pihakpihak yang terlibat didalamnya. Proses pemasaran dimana produk dari nelayan dialirkan ke konsumen membutuhkan suatu biaya yang dinamakan biaya pemasaran. Saluran pemasaran yang semakin panjang mengakibatkan semakin besar harga produk yang harus dibayar oleh konsumen. Efisiensi pemasaran ikan tenggiri di PPI Tanjungsari dapat dilihat pada Tabel 2 .

Berdasarkan analisis efisiensi yang telah dilakukan, nilai efisiensi saluran 1 memiliki nilai yang lebih kecil (20\%) dibandingkan saluran 2 (33\%). Berdasarkan Soekartawi (2002), kedua saluran tersebut termasuk tidak efisien dikarenakan nilainya lebih dari 5\%. Pada saluran pemasaran 2, jumlah produksi rata-rata per hari mencapai $850 \mathrm{~kg}$ dengan biaya pemasaran sebesar Rp 25.148,-/kg. Hal ini disebabkan karena pedagang besar mengeluarkan biaya transportasi yang tinggi dikarenakan harus mengirimkan ikan Tenggiri ke luar Kabupaten Pemalang. Hal ini diperkuat oleh Rasidin dan Raman (2018), efisiensi pemasaran dipengaruhi juga oleh efisiensi sistem transportasi yang menghubungkan lokasi produsen dan konsumen karena biaya transportasi akan mempengaruhi harga penawaran.

Tabel 1. Marjin pemasaran ikan tenggiri di PPI Tanjungsari

\begin{tabular}{lccc}
\hline Pelaku Usaha & $\begin{array}{c}\text { Harga Beli } \\
\text { (Rp/kg) }\end{array}$ & $\begin{array}{c}\text { Harga Jual } \\
\text { (Rp/kg) }\end{array}$ & $\begin{array}{c}\text { Marjin Pemasaran } \\
\text { (Rp/kg) }\end{array}$ \\
\hline $\begin{array}{c}\text { Saluran } \\
\text { Pemasaran 1 }\end{array}$ & & & - \\
\hline Nelayan & - & 43.424 & 14.676 \\
Pedagang Sedang & 43.424 & 58.100 & 7.950 \\
Pedagang Kecil & 58.100 & 66.050 & - \\
Konsumen Akhir & 66.050 & - & - \\
\hline \multicolumn{1}{c}{ Saluran } & & & 21.576 \\
\hline Pemasaran 2 & - & 43.424 & 11.667 \\
Nelayan & 43.424 & 65.000 & - \\
Pedagang Besar & 65.000 & 76.667 & - \\
Konsumen Akhir & 76.667 & & - \\
\hline
\end{tabular}


Tabel 2. Efisiensi Pemasaran Ikan Tenggiri di PPI Tanjungsari

\begin{tabular}{clccc}
\hline $\begin{array}{c}\text { Saluran } \\
\text { Pemasaran }\end{array}$ & \multicolumn{1}{c}{ Pelaku Usaha } & $\begin{array}{c}\text { Biaya Pemasaran } \\
\text { (Rp/Kg) }\end{array}$ & $\begin{array}{c}\text { Efisiensi } \\
\text { Pemasaran (\%) }\end{array}$ & $\begin{array}{c}\text { Status } \\
\text { Efisiensi }\end{array}$ \\
\hline \multirow{2}{*}{1} & Nelayan & & & \\
& Pedagang Sedang & 8.601 & 20 & Tidak Efisien \\
& Pedagang Kecil & 4.526 & & \\
& Konsumen & & & Tidak Efisien \\
& Nelayan & 18.177 & 33 & \\
& Pedagang Besar & 6.971 & &
\end{tabular}

Selain biaya transportasi, biaya pemasaran ikan tenggiri juga mencakup biaya retribusi, biaya jasa angkut, dan biaya pengawetan menggunakan es. Biaya retribusi TPI yang dikenakan untuk nelayan sebesar $3 \%$, dan untuk pedagang sebesar $2 \%$. Menurut Huda et al. (2015), harga ikan muncul disebabkan mulai dari harga penjualan di TPI. Di pihak distributor juga terdapat biaya pemasaran yang mengakibatkan terjadinya margin karena harus mengeluarkan biaya-biaya lainnya, seperti biaya membeli ikan dari TPI, biaya jasa angkut dari TPI menuju kendaraan, biaya pemberian es untuk mengawetkan ikan, biaya BBM kendaraan, upah sopir kendaraan, biaya retribusi, dan biaya resiko, serta perlu dihitung berapa besar pengambilan keuntungannya. Biaya yang harus dikeluarkan tidak hanya itu saja, melainkan juga terdapat biaya penanganan dan pengambilan keuntungan yang harus didapatkan oleh pedagang di pasar regional, pasar kabupaten, dan pasar kecamatan. Hal ini menyebabkan terjadinya kenaikan harga ikan di tiap pelaku usaha yang ada di dalam alur distribusi ikan tersebut.

Untuk meningkatkan efisiensi pemasaran ikan Tenggiri di PPI Tanjungsari Kabupaten Pemalang, diperlukan adanya integrasi fungsional antara sentra produksi komoditas perikanan tangkap dengan daerah sentra konsumsi. Hal ini sesuai dengan penelitian Riswandi dan Oktariza (2015) yang menyebutkan bahwa strategi yang dapat dilakukan diantaranya adalah menyediakan informasi pasar yang terpadu antara sentra pemasaran dengan berbagai sentra produksiperikanan tangkap, terutama mengenai informasi harga dan prakiraan pasokan yang termutakhir. Strategi yang lain adalah menetapkan harga pokok pada beberapa jenis ikan yang mempunyai share besar terhadap produksi maupun konsumsi masyarakat dan juga menetapkan batas margin yang diperbolehkan diambil oleh pelaku pemasaran hasil perikanan. Strategi-strategi tersebut diharapkan dapat menurunkan harga ikan Tenggiri di tingkat konsumen akhir, terdapat pembagian yang adil di antara pelaku pemasaran dari harga keseluruhan yang dibayarkan oleh konsumen, dan juga pemasaran bisa menjadi lebih efisien.

\section{KESIMPULAN DAN SARAN}

\section{Kesimpulan}

Pelaku usaha pemasaran ikan Tenggiri di PPI Tanjungsari terdiri dari nelayan, pedagang skala besar, sedang, kecil, dan pedagang luar kota dengan 2 model saluran pemasaran, yaitu saluran 1 dari nelayan, pedagang skala sedang, pedagang skala kecil, konsumen lokal Kabupaten Pemalang; dan saluran 2 dari nelayan, pedagang skala besar, pedagang luar kota, dan konsumen akhir. Saluran 1 memiliki total marjin pemasaran sebesar Rp $22.626,-/ \mathrm{kg}$, dan saluran 2 memiliki total marjin pemasaran sebesar Rp 33.243,-/ $\mathrm{kg}$. Analisis efisiensi pemasaran didapatkan hasil bahwa kedua saluran tersebut termasuk ke dalam kategori tidak efisien dikarenakan tingginya harga ikan Tenggiri yang harus dibayarkan oleh konsumen akhir.

\section{Saran}

Penyediaan informasi harga pasar sangat diperlukan untuk meningkatkan efisiensi pemasaran dan pendapatan nelayan, agar dapat dijadikan acuan bagi 
nelayan untuk penentuan harga di TPI. Selain itu, penetapan harga pokok dan pembatasan marjin yang diperbolehkan diambil oleh pelaku pemasaran juga perlu diatur agar harga ikan di tingkat konsumen akhir tidak semakin tinggi.

\section{UCAPAN TERIMA KASIH}

Penulis mengucapkan terima kasih kepada Dinas Kelautan dan Perikanan Kabupaten Pemalang, Bapak Rosidi selaku Ketua TPI Tanjungsari, Kabupaten Pemalang dan Bapak Nurokhim selaku Kepala KUD Mina Misoyo Sari Kabupaten Pemalang, dan Lukyta Dwika Ali Ashar yang telah membantu dalam kelengkapan data primer dan sekunder.

\section{DAFTAR PUSTAKA}

Badan Pusat Statistik Jawa Tengah. 2017. Produksi Peikanan Laut yang Dijual di Tempat Pelelangan Ikan Provinsi Jawa Tengah 2017. BPS Jawa Tengah, Semarang.

Dinas Kelautan dan Perikanan Kabupaten Pemalang. 2019. Laporan Tahunan Kabupaten Pemalang. DKP, Pemalang.

Hanafiah AM, Saefuddin AM. 1986. Tata Niaga Hasil Perikanan. UI-Press, Jakarta.

Hapsari TD. 2014. Distribusi dan Margin Pemasaran Hasil Tangkapan Ikan Tongkol (Euthynnus affinis) di TPI Ujungbatu Jepara. Aquasains. 2(2): 131-138.

Huda M, Solihin I, Lubis E. 2015. Tingkat Efisien Pemasaran Ikan Laut Segar di Pelabuhan Perikanan Nusantara Brondong. Jurnal Teknologi Perikanan dan Kelautan. 6(1): 91104.

Ismail G, Supardi S, Wahyuningsih S. 2008. Analysis Efficiency Marketing System of Fresh Layang Fish (Decapterus russeli) on Pelabuhan Fish Auction Place in Tegal City. Jurnal Mediagro 39. 4(2): 39-50.

Kaygisiz F, Eken M. 2018. A Research on Determination of Fish Marketing Margins in Istanbul Province of Turkey. Turkish Journal of Fisheries and Aquatic Sciences. 18: 801-807.

Kotler P. 2005. Manajemen Pemasaran (Terjemahan). PT. Prenhalindo, Jakarta.

Rasidin Y, Raman. 2018. Analisis Pendapatan dan Efisiensi Pemasaran Cabai Merah (Capsum annum L.) di Kecamatan Watangpulu Kabupaten Sidrap. Jurnal Pendidikan Teknologi Pertanian. 4(2): 112-122.

Riswandi DI, Oktariza W. 2015. Analisis Margin dan Efisiensi Pemasaran Ikan Bandeng dan Ikan Tongkol di DKI Jakarta. Jurnal Sains Terapan. 5(1): 60-73.

Sarwanto C, Wiyono ES, Nurani TW, Haluan J. 2014. Kajian Sistem Pemasaran Ikan Hasil Tangkapan Nelayan di Kabupaten Gunungkidul, Provinsi DIY. Jurnal Sosek KP. 9(2): 207-217.

Soekartawi. 2002. Agribisnis - Teori dan Aplikasinya. PT. Raja Grafindo Persada, Jakarta.

Sudana IW. 2019. Analisis Efisiensi Pemasaran Ikan Teri Segar Hasil Tangkapan Nelayan di Desa Sanggalangit Kabupaten Buleleng. Jurnal Pendidikan Ekonomi. 11(2): 637-648.

Sugiyono. 2012. Metode Penelitian Kuantitatif, Kualitatif dan R\&D. Alfabeta, Bandung.

Swastha B. 2002. Azas-Azas Marketing. Edisi II. Liberty, Yogyakarta.

Yusrin FL, Mudzakir AK, Sardiyatmo. 2017. Analisis Komoditas Unggulan Perikanan Tangkap di Kabupaten Pemalang. Journal of Fisheries Resources Utilization Management and Technology. 6(4): 276-283. 